\title{
Act-based versus harm-based sanctions for environmental offenders
}

Thomas Blondiau Sandra Rousseau
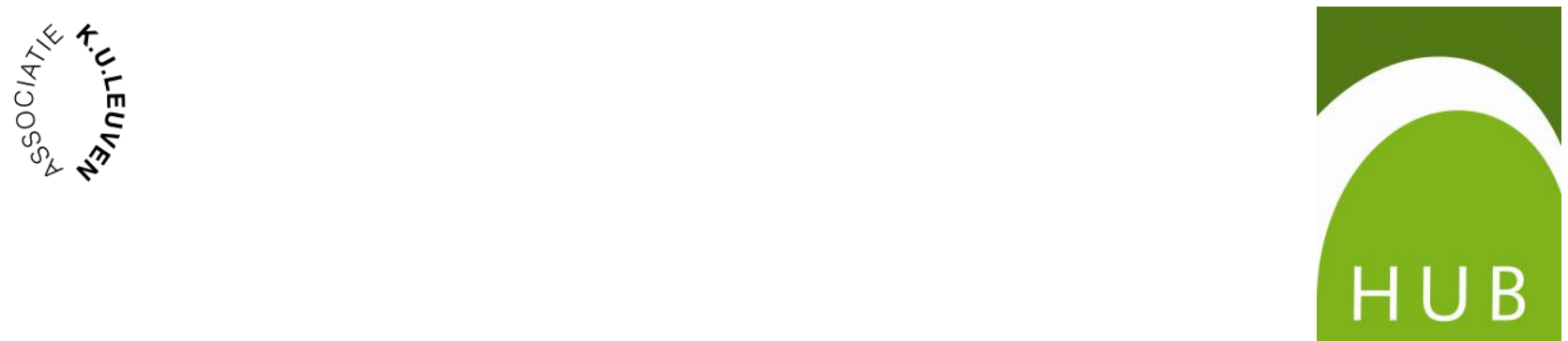


\title{
ACT-BASED VERSUS HARM-BASED SANCTIONS FOR ENVIRONMENTAL OFFENDERS ${ }^{1}$
}

\author{
Thomas Blondiau ${ }^{\mathrm{a},}$ and Sandra Rousseau ${ }^{\mathrm{b} 2}$ \\ ${ }^{a}$ CES, KU Leuven, Naamsestraat 69, B-3000 Leuven, Belgium \\ \& IDEA Consult, Kunstlaan 1-2, B-1000 Brussel, Belgium \\ ${ }^{b}$ FEB, HUBrussel, Warmoesberg 26, B-1000 Brussel, Belgium, \\ \& CES, KU Leuven, Naamsestraat 69, B-3000 Leuven, Belgium,
}

\begin{abstract}
We investigate the design of harm-based and act-based sanctions for environmental offenses. Empirical evidence for Belgium concerning both criminal and administrative sanctions clearly shows that the determination of harm-based and act-based sanctions for environmental offenses is less straightforward than theory predicts. In criminal cases, harm-based sanctions are influenced by offense related factors and specifically by the environmental harm caused, while the level of act-based sanctions is found to be independent of offense characteristics. Offender characteristics have a similar impact on the level of harm-based as well as act-based sanctions, with the exception of the treatment of facilities. In administrative cases, both types of sanctions positively depend on the seriousness of harm, respectively potential harm, caused. As a rule, we find that sanction levels increase for repeat offenders and decrease for offenders who took actions to minimize (potential) damages. Moreover, the analysis provides evidence of multiple objectives pursued by enforcing authorities.
\end{abstract}

Keywords: Enforcement; Environmental regulation; Criminal and administrative penalties; Environmental crime

\footnotetext{
${ }^{1}$ We gratefully acknowledge the SBO-IWT project 060034 (www.environmental-lawforce.be) for its financial support.

${ }^{2}$ Corresponding author: Tel (+32) 260982 75, Fax: (+32) 221764 64, Email: sandra.rousseau@kuleuven.be
} 


\section{Introduction}

In general, environmental offenses are penalized under two types of circumstances: firstly, when an offense caused actual harm, and secondly, when an offense involved risky behavior or potentially harmful acts without the actual occurrence of harm. Examples of the first category include the destruction of natural habitats, emissions of hazardous pollutants and soil contamination caused by illegal disposal of waste; while examples of the second category include missing documents such as maintenance or fire reports, producing goods or services with an inappropriate environmental permit and the inaccessibility of measuring points for water sampling. The two types of sanctions associated with these types of offenses are called harmbased and act-based sanctions respectively.

Past research has already looked at the distinction between ex ante and ex post legislative design given these two types of offenses. One strand of the literature has focused on ex post liability compared to ex ante regulation (see, among others, Wittman, 1984; Kolstad et al., 1990; Innes, 2004). However, the arguments centered around the distinction between private action versus public enforcement. Another strand of literature has focused on the general structure of law enforcement. Shavell (1993) and Polinshy and Shavell (1994) have, for instance, discussed actbased versus harm-based enforcement from the point of view of choosing the appropriate timing for an intervention: after the risky act has been committed or after the harm has been observed. More recently, Garoupa and Obidzinski (2011) investigate the efficiency of harm-based and actbased sanctions. They find that for equal deterrence levels, a system based on harm-based sanctions is cheaper since fewer offenders are convicted, it provides incentives to acquire information concerning harm and introduces appropriate incentives to control the occurrence of harm compared to a system based on act-based sanctions. Moreover, they state that the most serious disadvantage of using harm-based sanctions is the higher likelihood that offenders will be unable to pay the appropriate fine (judgment proofness). Further, looking specifically at the differences between act-based sanctions and harm-based sanctions, Polinsky and Shavell (2000) show that act-based sanctions need not be as high to accomplish a given level of deterrence and thus their impact on risk averse individuals is different. Finally, Garoupa and Obidzinski (2011) observe that act-based and harm-based sanctions may differ in the ease with which they can be applied. First, when acts are not easy to observe (such as carelessness when handling hazardous substances) or when expected harm is hard to calculate, harm-based sanctions should prevail. Second, when harm is hard to assess or when acts are easy to observe, act-based sanctions should be used by the regulator. 
While most of the literature on the design of optimal sanctions ${ }^{3}$ focusses on offenses that actually caused harm, little attention has been paid to the design of the optimal act-based sanctions. However, ignoring detection and prosecution costs, Polinsky and Shavell (2000) do state that for offenses causing harm the optimal expected sanction should equal the harm caused, while for offenses involving the risk - but not the actual occurrence - of harm the optimal expected sanction should equal the expected harm. This is quite a straightforward result, which might explain the lack of research effort spend on this topic. In this contribution we confront theory with practice and investigate whether the determinants of act-based and those of harm-based sanctions are indeed similar, with exception of the impact of the size of the harm or potential harm on the sanction level.

Therefore, we use data concerning the criminal environmental sanctions imposed on firms as well as individuals by courts of first instance in Flanders (one of three regions in the federal state Belgium) and the administrative environmental fines imposed by the administration in Brussels (another region in Belgium). Since over $80 \%$ of environmental legislation in Flanders and Brussels is directly based on European environmental directives, which are identical for all 27 EU member states, our results are likely to be relevant for and extend to a broader context than the Flemish or Brussels context. We find that judges and administrators do not take the same factors into account when determining the level of act-based sanctions and harm-based sanctions. Part of the differences are explained by the fact that several harm-related factors are taken into account when determining harm-based sanctions, which is not possible for act-based sanctions. However, some differences are not so easily explained. For instance, facilities can expect significantly higher criminal sanctions than individuals for offenses which caused actual harm, while the two types of offenders are treated equally for offenses which did not actually cause harm. Moreover, the same observation can be made for the administrative sanctions that are imposed which suggests that this might be a general phenomenon, at least in Belgium. The differences observed in practice concerning the determination of sanctions imposed for offenses related to actual harm and those related to potential harm are intriguing and invite additional theoretical as well as empirical - research on the design of optimal act-based versus harm-based sanctions.

\footnotetext{
${ }^{3}$ Following Becker's paper in 1968, one strand of literature points out that fines should be maximal, since raising fines is cheaper than increasing the likelihood of detection. However, to preserve marginal deterrence, Shavell (1992) and Mookherjee \& Png (1994) argue that fines should be an increasing function of the severity of the violation(s), and thus maximal fines are not optimal. So, the literature provides straightforward results (see, e.g., Polinsky \& Shavell, 1979, 1992; Garoupa, 2001): the regulator should set the optimal fine equal to the harm caused corrected for the probability that the violator is sanctioned (while taking the costs of prosecution and detection into account). Rousseau \& Telle (2010) have studied the existence of this optimal fine for environmental crime.
} 
In the next section we provide an overview of previous theoretical and empirical studies concerning environmental sanctioning. In section III, we present our data for the empirical analysis. We describe our estimation results in section IV and discuss them in section V. Section VI ends with some general conclusions.

\section{Literature overview}

The influence of factors such as intent, the gain resulting from the offense and the (potential) harm caused by the offense on the level of the imposed fine can greatly vary depending on the occurrence of harm as well as on the objective functions of the enforcing authorities.

Firstly, we discuss sanctions for violations that actually caused harm. We start by looking at an enforcing authority who aims at maximizing social welfare. Hence, the imposed sanctions aim at forcing economic agents to take external costs (i.e. environmental harm) into account. As shown by, among others, Polinsky and Shavell $(1979,2000)$, the optimal expected fine then is based on the level of the harm caused. Next, we look at an enforcing authority who aims at maximizing compliance. Maximization of compliance can follow from principles such as the notion that rules should be obeyed or that crime should not be profitable. As is shown in the literature (see e.g. Cohen, 1999) this implies that environmental sanctions should by based on the size of the gain obtained by the offender due to the violation. The optimal sanction from this perspective should thus be independent of the level of the environmental damage caused by the offense.

Secondly, when no actual harm occurred (yet) but agents displayed risky behavior, sanctions can be called risk-based or act-based sanctions (Shavell, 1993). As outlined by Innes (2004), this type of regulation may be preferred in case of serious environmental hazards. Garoupa and Obidzinski (2011) state that enforcement of act-based cases should in general be less stringent in terms of sanctioning levels and number of prosecution cases compared to harm-based cases. Again we start by looking at an enforcing authority who maximizes social welfare. The optimal fine then positively depends on the level of potential harm as well as the probability that an incident could have happened (Polinsky and Shavell, 2000). Next, when we look at an enforcing authority that maximizes compliance, the optimal act-based fine is independent of the size of the environmental harm that could have been caused and depends on the amount of compliance costs saved by the offender as well as the probability that an incident could have happened.

For a general overview of the theoretical and empirical issues associated with the sanctions imposed for environmental crime, we refer to Cohen (1999) and Rousseau (2009). With respect 
to penalty setting, three major categories of information are typically taken into account in sentencing in reality (see, e.g., Fox \& Freiberg, 1999; Australian Law Reform Commission, 2002):

- the particular circumstances of the offense such as its gravity compared to others in the same category; social danger; harm actually done; the prevalence of the type of offense; and the degree to which offenders are responsible for the offense;

- the characteristics of the offender that may mitigate his or her culpability for the offense or indicate the likelihood or otherwise of re-offending such as recidivism, the role of the individual in the corporation, and size of the offending corporation;

- the general aims of the penalty, to achieve one or more of the following: to exact retribution; deter others from committing similar offenses; rehabilitate the offender; denounce the action; and protect the community.

As noted by Rousseau (2009), the limited number of empirical studies investigating the determinants of penalties for environmental violations is striking. Moreover, the geographical scope of the studies is limited as well, since the majority deals with North American data. Nonetheless, these previous studies can be used to look at the empirical importance of the different categories of penalty determinants.

Concerning the circumstances of the offense, it is noteworthy that previous studies (see, for instance, Cohen, 1987; Earnhart, 1997, 2000; Kleit et al., 1998; Lynch et al., 2004; Blondiau \& Rousseau, 2010) routinely include some measure of the harm caused by the violation, but only a few studies included a proxy for the possible benefit from the violation. For example, Deily and Gray (1991) and Gray and Deily (1996) include an estimate of the compliance costs for the facilities; however, this variable was statistically not significant. Thus the analyses performed so far do not allow us to establish whether gain-related factors influence the level of monetary fines. In the current study, we therefore explicitly aim to take gain-related factors into account. The empirical evidence derived from the included harm-related variables makes it clear that penalty amounts generally increase with the seriousness of the violation (see, for instance, Deily \& Gray, 1991; Cohen, 1997; Earnhart, 1997, 2000; Kleit et al., 1998; Lynch et al., 2004; Blondiau \& Rousseau, 2010). Penalties were found to increase, for example, with the number of violations, with the amount of measured damages, or with the presence of third parties that were harmed. Also, remedial actions were taken by the violator to limit the harm caused were found to lower the penalty. However, none of these empirical studies explicitly distinguish between actual harm 
and potential harm. Further intent-related factors were also found to matter in previous empirical studies. Several studies (e.g. Cohen, 1987; Earnhart, 1997) incorporate variables relating to the cause of the offense. When the cause was related to human influence or negligence, the penalty imposed was significantly higher. Also, when the offense was labeled as being intentional, the penalty increased significantly (see, e.g., Oljaca et al., 1998).

Secondly, the characteristics of the offender also matter in practice. Studies typically find significant results for the variables relating to the size of the offending facility. However, the findings seem to be contradictory: whereas Oljaca et al. (1998) observed fines increasing with the number of employees employed by the violator, Lynch et al. (2004) found the opposite effect. Moreover, penalties significantly increase for repeat offenders. Studies that account for the number of past violations (e.g. Oljaca et al., 1998) or the past compliance status (e.g. Gray \& Deily, 1996) all found evidence corroborating this result.

Finally, in principle political and institutional factors should not matter in setting penalties, but the evidence suggests that in practice they do. For instance, a republican president in power in the US led to lower environmental fines (Ringquist, 1998). Also, during the communist regime in the Czech Republic military and foreign facilities were favorably treated compared to the following democratic regime (Earnhart, 1997). Moreover, several studies point to the importance of sanctioning procedures, e.g. fines increased with the number of defendants in White (2006).

Next we use a dataset of environmental sanctions for Belgium to investigate the possible differences between the determination and use of act-based and harm-based sanctions in reality.

\section{Data}

First, we describe the dataset we are using and then we look at the dependent and explanatory variables that are included in the estimation of the sanction level.

\subsection{Dataset}

The database contains information on criminal sanctions as well as administrative sanctions for environmental violations. The criminal sanctions are imposed by the Courts of First Instance in seven judicial districts of the Flemish region in Belgium ${ }^{4}$. In total, we dispose of 1313 first instance judgments being made between 2003 and 2006. The administrative sanctions are

\footnotetext{
${ }^{4}$ More information on the design of the database can be found in Billiet et al. (2009).
} 
imposed by the Brussels Environmental Agency (BIM). We dispose of 610 fining decisions that were imposed between 2004 and 2006.

In this dataset, we distinguish between 'harm' cases and 'no harm' cases. These groups correspond to defendants that actually caused environmental harm and defendants who face accusations of displaying risky behavior or causing environmental hazards. For making a distinction between the two cases, we base ourselves on indications related to the type of contamination. A significant share of the offenses carried the indication that "no contamination was caused'. Thus, the motivation of the sanctions imposed on these defendants cannot be based on actual environmental harm estimates. Most of the cases with no contamination recorded involved offenses in which a defendant did not fulfill a legal requirement such as filing for an environmental permit. An alternative group of 'no-harm' cases are certain cases dealing with noise nuisance where the rationale for deterrence is the possibility that (repeated) exposure to loud music/noise may cause hearing damage. The remaining group of defendants, for whom there was an indication that their violations resulted in environmental harm, are categorized as 'harm' cases. For the group of defendants that face both 'harm' and 'no-harm' offenses, we assume that the offenses leading to actual environmental harm are the most important for determining the level of the sanction. Therefore, we categorize these defendants among the 'harm' group.

Table 1: Number of defendants in each subset

\begin{tabular}{|l|c|c|}
\hline Number of defendants in each subset & Harm & No harm \\
\hline Criminal track & 1048 & 265 \\
\hline Administrative track & 276 & 334 \\
\hline
\end{tabular}

As is shown in table 1, the share of 'no harm' cases is much lower in the criminal than in the administrative enforcement track (20.2\% versus 54.8\%), which is in accordance with the statement of Garoupa and Obidzinski (2011) that criminal sanctions are more likely to be harmbased and administrative ones are more often risk-based.

\subsection{Dependent variables}

We now outline the construction of the dependent variables to measure the stringency of the sanction in the criminal and the administrative track. For the criminal sanctions, we focus on the principal penalties, which are fines and prison sentences, plus the amount of removal of illicit gain awarded. Each sanction imposed consists of an 'effective' component and a 'conditional' 
component. We restrict our attention to the effective component of the sanction and we only include proven accusations in our analysis, since cases where no sufficient proof is available automatically lead to acquittals. Some descriptive statistics can be found in Table 2 .

Table 2: Descriptive statistics for effective criminal sanctions imposed

\begin{tabular}{|l|c|c|c|c|c|}
\hline Variable & $\begin{array}{c}\text { Number of } \\
\text { observations }\end{array}$ & Average & Median & Maximum & Minimum \\
\hline Fine (in $€$ ) & 991 & 4807 & 1000 & 475000 & 55 \\
\hline $\begin{array}{l}\text { Imprisonment } \\
\text { (in months) }\end{array}$ & 33 & 5,4 & 3 & 24 & 1 \\
\hline $\begin{array}{l}\text { Removal of illegal } \\
\text { gain (in } € \text { ) }\end{array}$ & 64 & 403841 & 12701 & 24212597 & 500 \\
\hline
\end{tabular}

Note that the distribution of the fine levels is skewed to the right, thus lower sanctions occur more frequently than higher sanctions. The same holds for the requested removal of illicit gain by the public prosecutors. To perform a consistent empirical estimation, we construct one value (CRISANC) to indicate the stringency of the sanction which is based on the three components of Table 2. Therefore, we need to find an equivalent monetary value for a jail sentence. To this end, we use the transformation coefficient used by the Belgian regulator to transform the legal prison sentences that can be imposed on natural entities into the maximum fines that can be imposed on legal entities (see also Billiet et al., 2009). Thus, the variable LN(CRISANC) represents the logarithmic transformation of the level of the effective sanction defined as the sum of the monetary equivalent of an imposed prison sentence, the effective fine and the awarded removal of illicit gain. In our dataset (Billiet et al., 2009), judges of the courts of first instance convicted three in four defendants. Moreover, one in eight defendants were acquitted, while for the remaining defendants without a conviction the verdict was suspended.

For the administrative cases, the dependent variable is equal to the imposed fine (ADMSANC) and the variable $\mathrm{LN}(\mathrm{ADMSANC})$ represents the logarithmic transformation of the administrative fine level. In our dataset, an administrative fine was imposed in $62 \%$ of the cases in which the fining procedure was started. Some descriptive statistics on the level of administrative fines are given in Table 3. The average fine is significantly higher than the median, so its distribution is again skewed to the right.

Table 3: Descriptive statistics for level of administrative fines 


\begin{tabular}{|l|c|c|c|c|c|}
\hline Variable & Count & Average & Median & Max & Min \\
\hline Amount (in $€$ ) & 399 & 3628 & 785 & 102915 & 62 \\
\hline
\end{tabular}

\subsection{Explanatory variables}

We subsequently present three groups of explanatory variables: those related to the offenses, those related to the offender and some additional control variables. Appendix A provides an overview of the variables, their definition and of enforcement tracks in which we use them to study the level of the sanctions.

Firstly, we look at the characteristics of the offenses. In the criminal track, we define the indicator variables NATURE, HEALTH and CIVIL PARTY to approximate the harm caused. These indicators are equal to one if (for at least one of the defendant's proven offenses) natural resources were affected, public health was affected or an affected third party was included in the case, respectively. Further, the variable DAMAGE is derived from the judge's motivation of the verdict and indicates his perception on the level of harm caused. DAMAGE equals 1 if the text mentions at least one of the terms 'damage', 'lack of respect for the environment', 'pollution' or 'contamination'. We also include a count variable for the number of proven offenses since one prosecution can bundle several offenses in one case; this variable is called OFFENSES. To measure the extent of harm in the administrative track, we use the same variables as in the criminal track, except that NATURE cannot be used due to insufficient observations, nor can CIVIL PARTY be used because third parties cannot be legally included in administrative cases in Belgium. We also include the variable ASBESTOS to analyze the administrative fining decisions. The dummy ASBESTOS indicates that the offense involved the toxic substance asbestos, thus causing serious environmental risk as well as health risks. Therefore, this variable can be interpreted as a proxy for high risk behavior. We also control for contamination type through the inclusion of four indicators: WASTE to indicate violations related to illegal waste disposal, NOISE for violations related to noise nuisance, SOIL-WATER for soil or water pollution offenses, and ODOR-AIR for violations that are related with odor or air pollution problems. Then, we control for cases related to AIRPLANE noise, because this is a quite specific and large group among the administrative enforcement cases. Finally, we include the dummy TECHNICAL for the administrative cases only. This dummy is equal to one if the offense was caused by some mechanical or technical failure, which indicates that the level of intent was probably rather low. In addition, we define a variable LNFORFEIT, which represents the (logarithmically transformed) amount of illicit gains (in euro) that the public prosecutor requested to be removed through a criminal trial. 
Secondly, we investigate some relevant characteristics of the offenders. In the criminal track, the perception on the degree of the offender's intentionality is measured by the variable INTENT. This indicator is created from the judge's written motivation statement (which is a mandatory complement for each verdict) and is equal to one if explicit statements ${ }^{5}$ were written down indicating that the offense is considered to have been purposely committed. The variable REPEAT was also derived from the written verdict and is equal to one if the judge mentions that the violator was a repeat offender and was previously convicted. Next, the dummy PREWARN equals one if the offense was reported by an administrative agency before being brought before a criminal court, which is a sign of warnings previous to trial. Also, an indicator GAIN is created to indicate whether judges explicitly mention the profit motive when justifying the verdict. GAIN equals one if the judge's motivation of the verdict included one of the following terms: 'pursuit of profit', 'economic profits', 'self-interest', 'financial profit' or 'economic stakes'. For the administrative cases, INTENT and REPEAT are defined analogously to the criminal cases. The PREWARN variable is now equal to one if the administrative agency set up a proof of default document before the defendant was brought to court, which is again a sign of warnings previous to trial. Next, we add the variable POSITIVE to indicate whether actions were undertaken by the defendant to mitigate the extent of environmental damages caused, or to reduce the level of the environmental risk in the 'no harm' case. Furthermore we control for the type of offender which can be a legal entity (FACILITY), an individual charged within his/her professional capacity (PROF), or an individual charged within his/her private capacity.

Finally, we also include a number of variables to control for regional differences and variations over time.

\section{Estimation}

First, we briefly discuss the estimation method used and next we present the results from the estimations for the criminal and administrative environmental sanctioning processes in respectively Flanders and Brussels.

\subsection{Estimation method}

We start by testing for differences in means between our two subsets - 'harm' versus 'no harm' using the non-parametric Wilcoxon rank-sum test. We find significant differences between the

\footnotetext{
${ }^{5}$ These statements include the use of the terms 'knowingly and willingly', 'sustained', 'intentionally', 'on purpose', 'purposely', or 'unwillingness'.
} 
means for the 'harm' and 'no harm' sanctioning decisions in the criminal as well as in the administrative sanctioning track. So, it is best to estimate two separate regression models for the 'harm' and 'no harm' subsets.

Thus, we estimate four regression models: two for each enforcement track and two for distinguishing between the 'harm' and 'no harm' cases. We estimate these models using ordinary least squares in which the level of the sanction is the dependent variable $F_{i}$. Further, the offense characteristics are denoted by $X_{\text {offense, }}$, the offender characteristics by $X_{\text {offender }}$, the control variables by $X_{\text {control }}, \beta_{i}$ represents the estimated coefficients and $u_{i}$ the error term. Formally, the OLS regression function can thus be written down as:

$$
F_{i}=\beta_{0}+\beta_{1} X_{\text {offense }}+\beta_{2} X_{\text {offender }}+\beta_{3} X_{\text {control }}+u_{i}
$$

We also estimate a two-step regression model to evaluate the robustness of the OLS coefficients. The regression results are represented in appendix $\mathrm{B}$. We first estimate a probit model of the probability that a sanction is imposed, in which the error term $\varepsilon_{i}$ is assumed to follow a standardnormal distribution:

$$
\operatorname{Pr}\left(\text { Sanction }_{i}=1 \mid X_{\text {offense }}, X_{\text {offender }}, X_{\text {control }}\right)=\Phi\left[\varepsilon_{i}>-\left(\beta_{0}+\beta_{1} X_{\text {offense }}+\beta_{2} X_{\text {offender }}+\beta_{3} X_{\text {control }}\right)\right]
$$

Next, we estimate the level of the imposed sanction, using the Inverse Mills Ratio (LAMBDA: $\Lambda_{i}$ ) as a correction term for possible sample selection bias (Heckman, 1979). In this equation, the coefficient for $\Lambda_{i}$ equals the covariance between the standard error of the probit regression model and the error of this linear specification:

$$
F_{i}=\beta_{0}+\beta_{1} X_{\text {offense }}+\beta_{2} X_{\text {offender }}+\beta_{3} X_{\text {control }}+\left(\rho^{*} \sigma_{\varepsilon} * \sigma_{v}\right) * \Lambda_{i}+v_{i}
$$

The differences between the results obtained by applying the two-step method with the results of the OLS approach are discussed in the text, while the estimated coefficients are provided in appendix B.

\subsection{Estimation results}

We start by discussing the empirical results of the criminal enforcement track, in which we separately analyze the cases where harm occurred and where no harm occurred. Next, we turn to the empirical results of the administrative enforcement track, in which 'harm' and 'no harm' cases are again separately analyzed.

\subsubsection{Criminal enforcement}


The estimation results for criminal enforcement of environmental offenses in Flanders are given in Error! Reference source not found.. First we discuss the results for the 'harm' cases and then turn to the 'no harm' cases.

Looking at the impact of the offense characteristics in the 'harm' group, we see that harm is an important determinant of the sanction, as we expected. Offenses that had negative health effects (HEALTH) are sanctioned significantly more severe. Also, sanction levels increase significantly for high DAMAGE offenses, for cases where CIVIL PARTIES are involved and for a higher number of OFFENSES committed. We also find that WASTE related offenses lead to higher sanction levels and that the requested FORFEITURE of illegal gains has a significant positive impact on the sanction level. Next, we look at how the offender characteristics influence the level of the sanction in the 'harm' group. We find that REPEAT and PREWARN positively influence the level of the sanction. Moreover, in cases where the economic benefits associated with the offense are regarded as an important element by the judge (GAIN), the sanction increases significantly. Offenders who reacted quickly to control and clean up the environmental harm (POSITIVE) incur a significantly lower sanction. Further, we see that facilities (FACILITY) are sanctioned significantly more severely than offenders who committed the offense in their private capacity. In contrast, individual offenders in official capacity (PROF) incur significantly lower sanctions. Finally, offenders in the regions of KORTRIJK and BRUGGE can expect lower sanctions, while we find no temporal effects.

When we estimate a two-step regression model with Heckman correction for sample selection for the harm cases, we generally find that the coefficients obtained in the OLS regression are quite robust (see appendix B). What we see is that some of our significant variables rather have an impact on the probability of sanction (REPEAT, HEALTH, WASTE), while others lead to higher sanction levels once the decision to impose a sanction has been taken (LNFORFEIT, DAMAGE, CIVIL PARTY, OFFENSES, PROF, FACILITY, BRUGGE, KORTRIJK).

We now investigate the results for the criminal 'no harm' cases. Surprisingly, none of the offense related characteristics seem to have a significant effect on the imposed sanction. However, looking at the impact of offender related variables, we again see that REPEAT offenders and offenders who received warnings prior to being brought to trial (PREWARN) can expect significantly higher sanction levels. Also, the judicial perception on the violations' profitability (GAIN) positively influences the sanction level. POSITIVE actions taken to limit the environmental hazards after the offense lead to lower sanctions, ceteris paribus. Finally, we see that PROF offenders incur lower sanctions and that in the jurisdiction of BRUGGE sanctions are significantly lower. When we estimate a two-step regression model (see appendix B), we see that 
the significant effects for the variables REPEAT, PREWARN, POSITIVE and PROF are all mainly due to an increase or decrease in the sanction probability, rather than in the sanction level.

Table 4: Estimation of criminal sanction level for 'harm' and 'no harm' cases

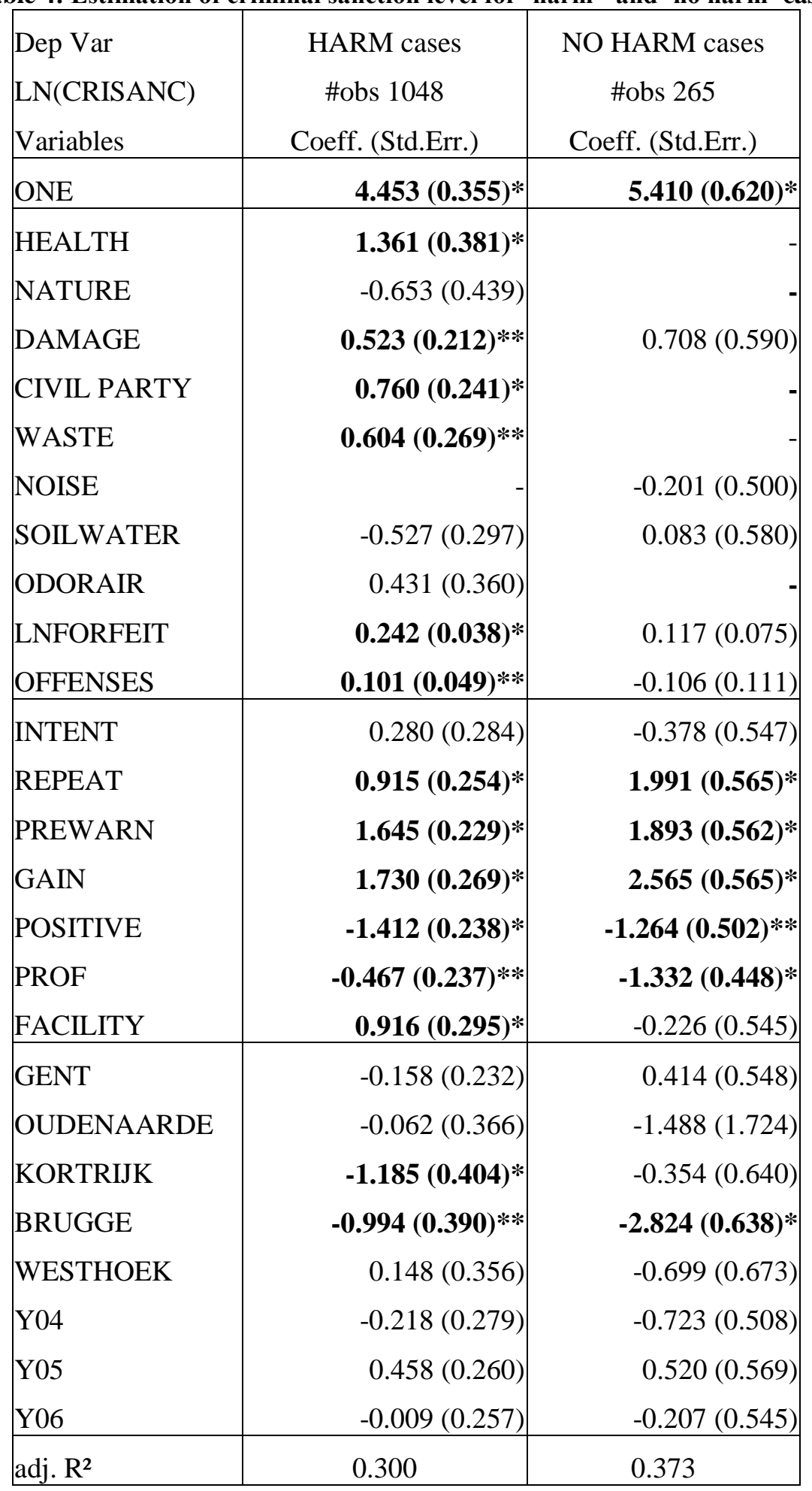


** indicates statistical significance at $1 \%$ level. * at $5 \%$ level

\subsubsection{Administrative enforcement}

We now address the regression results for the administrative enforcement track, see Error! Reference source not found.

Table 5: Estimation of administrative sanction level for the 'harm' and 'no harm' cases

\begin{tabular}{|c|c|c|}
\hline & & \\
\hline & HARM & NO HARM \\
\hline Dep Var: LN(ADMSANC) & \#obs:276 & \#obs:334 \\
\hline Variables & Coeff. (Std.Err.) & Coeff. (Std.Err.) \\
\hline ONE & $1.378(0.700)^{* *}$ & $3.454(0.720)^{*}$ \\
\hline HEALTH & $1.803(0.388)^{*}$ & - \\
\hline TECHNICAL & $-1.031(0.457)^{* *}$ & - \\
\hline ASBESTOS & - & $1.143(0.490)^{* *}$ \\
\hline WASTE & - & $0.827(0.362)^{* * *}$ \\
\hline SOILWATER & $-0.311(0.471)$ & - \\
\hline ODORAIR & $0.494(0.520)$ & $-0.280(0.590)$ \\
\hline AIRPLANE & $1.809(0.483)^{*}$ & - \\
\hline OFFENSES & $0.109(0.027) *$ & $0.054(0.047)$ \\
\hline INTENT & $-1.301(0.682)$ & $-0.737(0.474)$ \\
\hline REPEAT & $1.749(0.393)^{*}$ & $0.548(0.486)$ \\
\hline PREWARN & $0.425(0.422)$ & $0.747(0.330)^{* *}$ \\
\hline POSITIVE & $-1.792(0.299)^{*}$ & $-3.312(0.309)^{*}$ \\
\hline PROF & $2.076(0.646)^{*}$ & $-0.036(0.701)$ \\
\hline FACILITY & $2.405(0.631)^{*}$ & $0.573(0.673)$ \\
\hline Y05 & $0.179(0.425)$ & $0.769(0.349)^{* *}$ \\
\hline Y06 & $0.070(0.432)$ & $0.854(0.382)^{* * *}$ \\
\hline $\operatorname{adj} R^{2}$ & 0.557 & 0.351 \\
\hline
\end{tabular}

** indicates statistical significance at $1 \%$ level, * at $5 \%$ level

We first discuss the empirical results for the 'harm' cases. Among the offense related variables, we find that negative HEALTH impacts lead to significantly higher sanctions, that sanctions 
increase with each additional offense (OFFENSES), and that in the cases where violators are AIRPLANE companies the average sanction is also significantly higher. Turning to the offender characteristics, we find that REPEAT offenders receive significantly higher sanctions. We see that offenses due to mechanical failures (TECHNICAL) are sanctioned significantly less severely and that sanctions also significantly decrease with POSITIVE actions. Finally, we find that FACILITY and PROF receive higher fines than private offenders. The results of the two-step regression confirm that the estimated OLS coefficients are quite robust. The main difference is that the PREWARN variable now has a significantly positive effect on the sanction level (after the sanctioning decision has been taken). The significant OLS coefficients for TECHNICAL, HEALTH and POSITIVE can mainly be attributed to changes in the sanction probability, rather than changes in the sanction level. The effect for AIRPLANE can be mainly attributed to a higher sanction level, rather than a higher sanction probability. The positive effect for the variable OFFENSES seems to be a combination of a higher probability and a higher level.

For the administrative 'no harm' cases, we observe that fines are higher in more 'risky' cases (ASBESTOS) as well as for WASTE related cases. Also, we see that fines increase when the offender previously received warnings (PREWARN) and that they are lower when the offender took POSITIVE actions to limit the risk. Finally, expected administrative fines are significantly higher in the years 2005 and 2006. The results for the two-step regression show that all the significant coefficients from the OLS regression can be explained by an increase in the sanction probability, rather than in the sanction level. However, there seems to be a higher sanction level for REPEAT offenders and for violators that are accused of committing multiple OFFENSES.

\section{Discussion of the results}

Based on the empirical analysis, we can comment on the similarities and differences between the determination of the level of harm-based versus act-based environmental sanctions.

Firstly, we concentrate on the criminal sanctioning decisions. While harm-based sanctions are clearly influenced by offense related factors and specifically by the environmental harm caused, the level of act-based sanctions is found to be independent of offense characteristics. Thus, as predicted by theory, harm-based sanctions are positively correlated by the level of harm caused. However, theory also predicted that act-based sanctions should depend on the expected level of harm that could been associated with the prosecuted risky behavior. Surprisingly, this prediction is not confirmed for our dataset. Further, we see that the offender characteristics have a similar impact on the level of harm-based sanctions as well as on the level of act-based sanctions, with 
the exception of the treatment of facilities. While facilities can expect to receive significantly higher harm-based sanctions than individuals, facilities are not treated differently than private individuals when it comes to act-based sanctions. Overall, repeat offenders are treated more severely, as were offenders that focused excessively on the pursuit of profit. Offenders investing in effort to reduce the (potential) environmental impact of the offense such as self-reporting violations could expect significantly lower sanctions.

Secondly, we look at the administrative enforcement track. Here both the impact of offense related factors and that of offender characteristics differ between harm-based and act-based sanctions. Both types of sanctions positively depend on the seriousness of harm, respectively potential harm, caused. Thus confirming theoretical predictions. Looking at the characteristics of the offender, we find that harm-based sanctions increase for repeat offenders, professionals and facilities and decrease for offenders who took measures to reduce the extent of the harm caused. Act-based sanctions, on the other hand, increase for offenders that previously received warnings and also decrease for offenders who took measures to reduce the extent of the environmental risk. It is also noteworthy that the level of harm-based sanctions was similar for the three years studied, while the level of act-based sanctions seems to increase over time.

To conclude, some similarities between criminal and administrative sanctions can be observed. Overall, sanction levels increase for repeat offenders and decrease for offenders who took actions to minimize (potential) damages. Harm-based sanctions increase with the level of harm. Facilities can expected higher harm-based sanctions, but similar act-based sanctions, compared to private individuals. However, we also note some differences between criminal and administrative sanctions. Regarding act-based sanctions, offense characteristics seem to have no impact in the criminal track, while they do have an impact in the administrative track. Moreover, an excessive focus on financial gains is treated as a negative factor in the criminal track and leads to higher sanctions, while this motive is not included as such in the administrative track.

Besides insight into the design of harm-based and act-based sanctions, our results also provide evidence of the objectives pursued by the enforcing authorities. For the criminal enforcement cases, we find different results for the judges' objective functions depending on the fact whether actual harm occurred or not. Based on the results for the harm cases, we find evidence of two objectives. The increasing expected sanctions associated with the gain related factors (GAIN and LNFORFEIT) point toward a desire to maximize compliance, while the increasing sanctions associated with the harm related factors (HEALTH, DAMAGE, CIVIL PARTY, OFFENSES and POSITIVE) point to a judicial objective function that includes social welfare maximization. Thus, judicial objectives can be described as a combination of both social welfare maximization 
and compliance maximization (see also Blondiau \& Rousseau, 2010). Regarding the 'no harm' cases, the results point much stronger towards compliance maximization than towards social welfare maximization.

Turning to the results for administrative enforcement, we find positive evidence of social welfare maximization for both 'harm' and 'no harm' cases. However, we find only indirect evidence of compliance maximization since there was little or no information available to identify a gain component. To start, it is not possible for the administration in Brussel to request for removal of illicit gains in administrative cases. In addition, the written motivations that accompany sanctioning decisions are much less elaborate in their description. One of the officers of the administrative enforcement agency in Brussels (BIM) explained us that: "Although economic profit or gain is one of the elements that is taken into account when determining the appropriate level of a particular fine, it is not always clear how to calculate the profits that violating persons or facilities have made. However, there are specific regulations for which exact calculations of profits, or costs avoided, is possible. For example, in the regulation on transformers containing PCBs, the cost of removal of these transformers is taken into account." Moreover, Billiet (2008), a judge of the Brussels' administrative court of appeal, mentions that BIM seems to take the illegal profit into account when calculating the level of the fine for PCB-related cases.

\section{Conclusion}

Using a recent dataset we investigated how the determination of harm-based and act-based sanctions happens for both criminal and administrative sanctions. Looking at the sanctioning decisions by courts of first instance in Flanders and the environmental administration in Brussels, we commented on similarities and dissimilarities between these two types of sanctions. Previous theoretical analyses are scarce and straightforward: to maximize social welfare, the optimal expected harm-based sanction should depend on the level of harm caused, while the optimal expected act-based sanction should depend on the expected level of harm associated with the offense (Polinsky \& Shavell, 2000). Or alternatively, if compliance maximization is the goal, the

optimal expected harm-based sanction as well as the optimal expected act-based sanction should depend on the level of benefits resulting from the offense.

The empirical evidence from both criminal and administrative sanctions clearly showed that the determination of harm-based and act-based sanctions for environmental offenses is less straightforward than theory predicts. In criminal cases, harm-based sanctions are influenced by offense related factors and specifically by the environmental harm caused, while the level of act- 
based sanctions is found to be independent of offense characteristics. Further, offender characteristics seem to have a similar impact on the level of harm-based as well as act-based sanctions, with the exception of the treatment of facilities. In administrative cases, both harmbased sanctions and act-based sanctions positively depend on the seriousness of harm, respectively potential harm, caused. Further harm-based sanctions increase for repeat offenders, professionals and facilities, while act-based sanctions increase for offenders that previously received warnings. As a rule, we find that sanction levels increase for repeat offenders and decrease for offenders who took actions to minimize (potential) damages. The differences observed in reality regarding the level of harm-based and act-based sanctions imposed for environmental offenses are intriguing and invite additional - theoretical as well as empirical research on the design of optimal act-based versus harm-based sanctions.

The analysis also provided evidence on the objectives pursued by enforcing authorities when sanctioning environmental offenders. The empirical evidence clearly indicates that enforcing authorities often pursue multiple objectives. Since the probability as well as the level of sanctions increase with the level of environmental harm, decisions made by courts and administration both point to social welfare maximizing behavior. The fact that the probability and level of sanctions increase with the illegal gain obtained from environmental violations indicates a desire by the enforcing authorities to maximize compliance. Thus, theoretical models limited to one particular objective function are likely to lead to results which are less relevant in practice. It is important to find ways of dealing with combinations of objectives when analyzing optimal sanctions. This would also improve communication between economic scholars, legal scholars and enforcing authorities. Conflicting opinions and results might simply be caused by an incorrect or partial specification of the relevant objective functions. 


\section{Bibliography}

Australian Law Reform Commission ALRC 2002. Securing compliance: Civil and administrative penalties in federal regulation. Discussion paper 65 www.austlii.edu.au/au/other/alrc/ publications/dp/65/

Becker G. 1968. Crime and punishment: An economic approach. Journal of Political Economy 76: 169-217.

Biliet C.M. 2008. Bestuurlijke sanctionering van milieurecht. Intersentia.

Billiet C.M., Rousseau S., Balcaen A., Meeus R., Styns K., De Meyer G., Vander Beken T., Lavrysen L. 2009. Milieurechtshandhaving: een databestand voor onderzoek naar de penale en bestuurlijke sanctioneringspraktijk. Tijdschrift voor Milieurecht 18(2): 128-150.

Blondiau T., Rousseau S. 2010. The impact of the judicial objective function on the enforcement of environmental standards. Journal of Regulatory Economics 37(2): 196-214

Cohen M. 1987. Optimal enforcement strategy to prevent oil spills: An application of a principalagent model with moral hazard. Journal of Law and Economics 30: 23-51

Cohen M. 1999. Monitoring and enforcement of environmental policy. In: Tietenberg T., Folmer H. (eds.), International yearbook of environmental and resource economics, Vol. III, Edward Elgar Publishers.

Deily M.E., Gray W.B. 1991. Enforcement of pollution regulation in a declining industry. Journal of Environmental Economics and Management 21: 260-274

Earnhart D. 1997. Enforcement of environmental protection laws under communism and democracy. Journal of Law and Economics 40: 377-402

Earnhart, D. 2000. Environmental crime and punishment in the Czech Republic: Penalties under firms and employees. Journal of Comparative Economics 28: 379-399

Fox R.G., Freiberg A. 1999. Sentencing: State and federal law in Victoria. Oxford University Press.

Garoupa N. 2001. Optimal magnitude and probability of fines. European Economic Review 45: 1765-1771.

Garoupa N., Obidzinski M. 2011. The scope of punishment: An economic theory. European Journal of Law and Economics 31(3), 237-247

Gray W.B., Deily M.E. 1996. Compliance and enforcement: Air pollution regulation in the US steel industry. Journal of Environmental Economics and Management 31: 96-111

Heckman J. 1979. Sample selection bias as a specification error. Econometrica 47: 153-161. 
Innes R. 2004. Enforcement costs, optimal sanctions and the choice between ex-post liabilitiy and ex-ante regulation. International Review of Law and Economics 24(1): 29-48

Kleit A.N., Pierce M.A., Hill R.C. 1998. Environmental protection, agency motivations and rent extraction: the regulation of water pollution in Louisiana. Journal of Regulatory Economics 13: $121-137$

Kolstad C.D., Ulen T.S., Johnson G.V. 1990. Ex post liability for harm vs. ex ante safety regulation: substitutes or complements? American Economic Review 80(4): 888-901

Lynch M.J., Stretesky P.B., Burns R.G. 2004. Determinants of environmental law violation fines against petroleum refineries: Race, ethnicity, income and aggregation effects. Society and Natural Resources 17: 343-357

Mookherjee D., Png I.P.L. 1994. Marginal deterrence in enforcement of law. The Journal of Political Economy 102(5): 1039-1066

Oljaca N., Keeler A.G., Dorfman J. 1998. Penalty functions for environmental violations: Evidence from water quality enforcement. Journal of Regulatory Economics 14: 255-264

Polinsky A.M., Shavell S. 1992. Enforcement costs and the optimal magnitude and probability of fines. Journal of Law and Economics 35: 133-148

Polinsky A.M., Shavell S. 1994. Should liability be based on the harm to the victim or the gain to the injurer? Journal of Law, Economics and Organization 10: 427-437

Polinsky A.M., Shavell S. 2000. The economic theory of public law enforcement. Journal of Economic Literature 38: 45-67

Polinsky A.M., Shavell S. 1979. The optimal tradeoff between the probability and magnitude of fines. American Economic Review 69(5): 880-891.

Ringquist E.J. 1998. A question of justice: Equity in environmental litigation, 1974-1991. Journal of Politics 60(4): 1148-1165.

Rousseau S. 2009. Empirical analysis of sanctions for environmental offenses. International Review of Environmental and Resource Economics 3: 161-194.

Rousseau S., Telle K. 2010. On the existence of the optimal fine for environmental crime. International Review of Law and Economics 30(4): 329-337

Shavell S. 1992. A note on marginal deterrence. International Review of Law and Economics 12: 345-355

Shavell S. 1993. The optimal structure of law enforcement. Journal of Law and Economics 36(1): 255-287.

White M.J. 2006. Asbestos litigation: Procedural innovations and forum shopping. Journal of Legal Studies 35: 365-398 
Wittman D. 1984. Liability for harm or restitution for benefit? Journal of Legal Studies 13(1): 57-80. 


\section{APPENDIX A: Definition of dependent and explanatory variables}

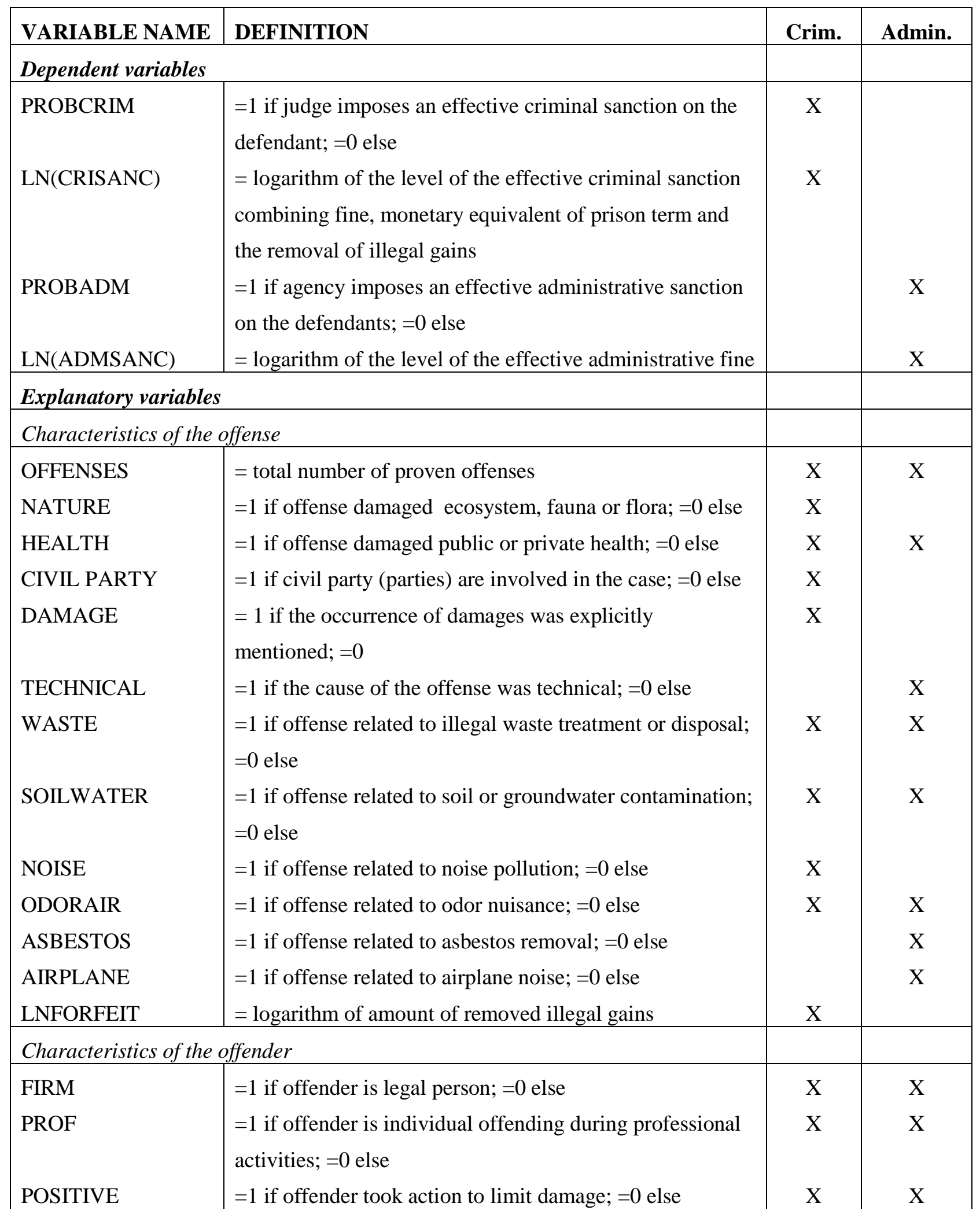




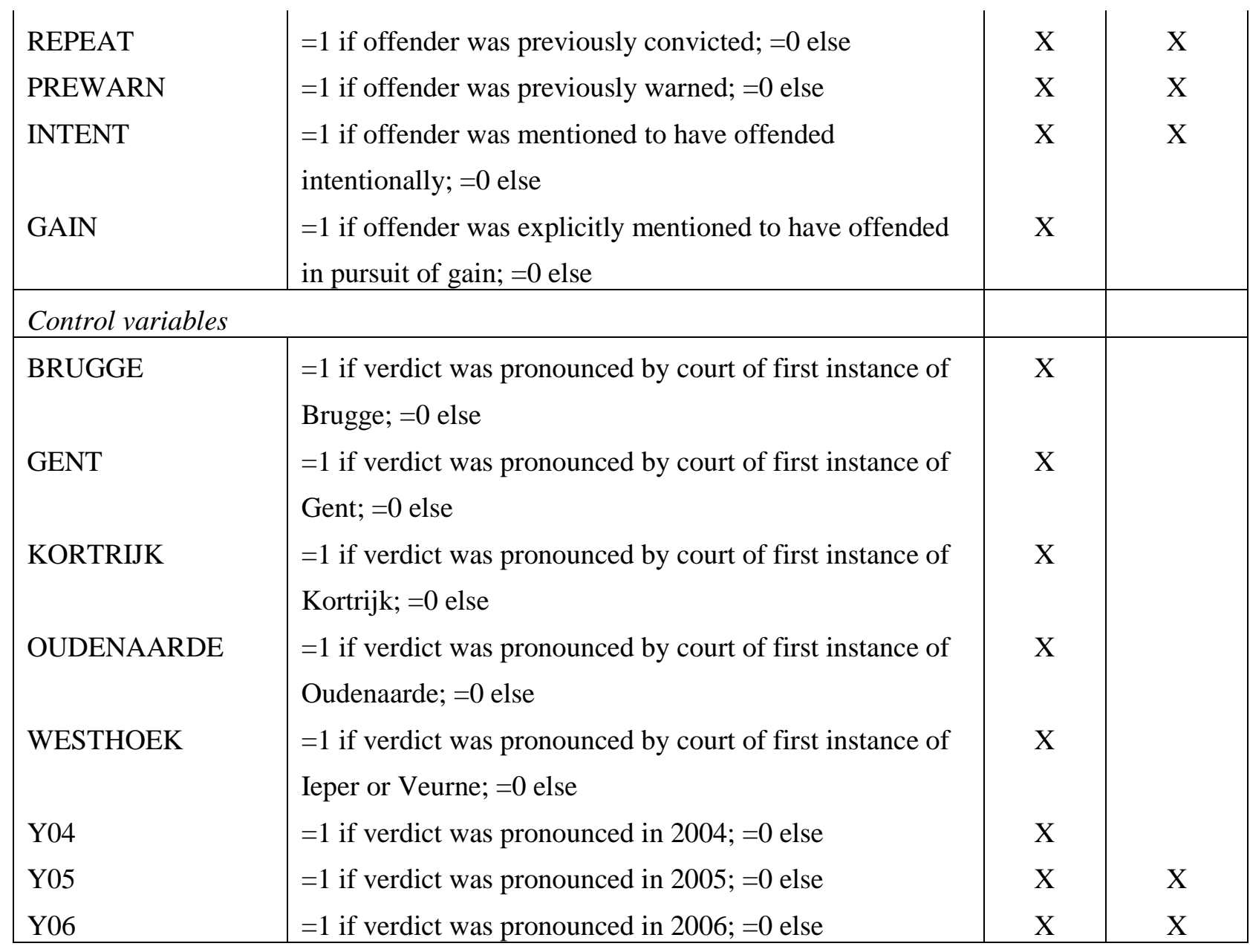




\section{APPENDIX B}

We define a variable PROBCRIM that equals one if the judge imposed an effective sanction on the defendant and equals zero if the verdict was postponed. The variable PROBADM equals one if an administrative fine was imposed and is zero otherwise.

Two-step regression model for criminal cases, using Heckman's correction for sample selection (** indicates statistical significance at $1 \%$ level, * at 5\% level):

\begin{tabular}{|c|c|c|c|c|}
\hline \multirow{5}{*}{ Variables } & \multicolumn{2}{|l|}{ HARM CASES } & \multicolumn{2}{|c|}{ NO HARM CASES } \\
\hline & PROBIT & SELECTION & PROBIT & SELECTION \\
\hline & $\begin{array}{l}\text { Dep Var } \\
\text { PROBCRIM }\end{array}$ & $\begin{array}{l}\text { Dep Var } \\
\text { LNCRISANC }\end{array}$ & $\begin{array}{l}\text { Dep Var } \\
\text { PROBCRIM }\end{array}$ & $\begin{array}{l}\text { Dep Var } \\
\text { LNCRISANC }\end{array}$ \\
\hline & \#obs: 1048 & \#obs: 920 & \#obs: 265 & \#obs: 196 \\
\hline & Coeff. (Std.Err.) & $\begin{array}{l}\text { Coeff. in } \\
\text { selection group } \\
\text { (Std.Err) }\end{array}$ & Coeff. (Std.Err.) & $\begin{array}{l}\text { Coeff. in } \\
\text { selection group } \\
\text { (Std.Err.) }\end{array}$ \\
\hline ONE & $0.938(0.230)^{*}$ & $5.496(0.487)^{*}$ & $1.530(0.357)^{*}$ & $6.829(0.559) *$ \\
\hline INTENT & $0.047(0.189)$ & $0.292(0.242)$ & $0.390(0.334)$ & $-0.743(0.588)$ \\
\hline REPEAT & $0.767(0.231)^{*}$ & $0.453(0.358)$ & $1.513(0.473) *$ & $1.079(0.973)$ \\
\hline PREWARN & $0.714(0.198) *$ & $1.181(0.338)^{*}$ & $1.050(0.407)^{* *}$ & $1.040(0.794)$ \\
\hline GAIN & $0.601(0.222)^{*}$ & $1.424(0.322)^{*}$ & & $1.594(0.442)^{*}$ \\
\hline LNFORFEIT & $-0.014(0.026)$ & $0.231(0.033)^{*}$ & $-0.021(0.040)$ & $0.130(0.096)$ \\
\hline HEALTH & $0.904(0.366)^{* * *}$ & $0.770(0.464)$ & & \\
\hline NATURE & $-0.492(0.269)$ & $-0.196(0.439)$ & & \\
\hline DAMAGE & $0.179(0.143)$ & $0.439(0.194)^{*}$ & $0.114(0.365)$ & $0.660(0.572)$ \\
\hline CIVIL PARTY & $0.296(0.169)$ & $0.607(0.237)^{* *}$ & & \\
\hline OFFENSES & $0.000(0.028)$ & $0.151(0.048)^{*}$ & $0.054(0.063)$ & $-0.144(0.122)$ \\
\hline POSITIVE & $-0.392(0.137)^{*}$ & $-1.216(0.275)^{*}$ & $-1.012(0.283)^{*}$ & $-0.737(0.799)$ \\
\hline WASTE & $0.503(0.167)^{*}$ & $0.104(0.324)$ & & \\
\hline NOISE & & & $0.184(0.324)$ & $-0.667(0.466)$ \\
\hline SOILWATER & $-0.021(0.182)$ & $-0.469(0.261)$ & $-0.343(0.299)$ & $-0.056(0.629)$ \\
\hline ODORAIR & $0.301(0.256)$ & $0.064(0.334)$ & & \\
\hline PROFESSIONAL & $-0.123(0.149)$ & $-0.444(0.209)^{* *}$ & $-0.692(0.261)^{*}$ & $-0.810(0.591)$ \\
\hline FACILITY & $0.252(0.193)$ & $0.796(0.275)^{*}$ & $-0.224(0.318)$ & $0.126(0.526)$ \\
\hline GENT & $-0.085(0.149)$ & $-0.179(0.200)$ & $-0.438(0.325)$ & $0.856(0.569)$ \\
\hline
\end{tabular}




\begin{tabular}{|l|r|r|r|r|}
\hline OUDENAARDE & $-0.141(0.226)$ & $0.072(0.321)$ & $-1.557(0.893)$ & $0.558(1.903)$ \\
\hline KORTRIJK & $-0.009(0.241)$ & $\mathbf{- 1 . 3 2 9}(\mathbf{0 . 3 5 1}) *$ & $-0.082(0.395)$ & $-1.064(0.580)$ \\
\hline BRUGGE & $-0.117(0.239)$ & $\mathbf{- 1 . 1 7 2}(\mathbf{0 . 3 4 7}) *$ & $\mathbf{- 1 . 3 3 3 ( \mathbf { 0 . 3 4 3 } ) *}$ & $\mathbf{- 2 . 7 3 2 ( \mathbf { 1 . 0 9 5 } ) * *}$ \\
\hline WESTHOEK & $-0.167(0.223)$ & $0.286(0.313)$ & $\mathbf{- 1 . 1 7 5}(\mathbf{0 . 3 4 8}) *$ & $0.572(1.051)$ \\
\hline Y04 & $\mathbf{- 0 . 3 9 1 ( \mathbf { 0 . 1 8 0 } ) * *}$ & $0.134(0.288)$ & $-0.083(0.289)$ & $-0.613(0.504)$ \\
\hline Y05 & $-0.093(0.178)$ & $\mathbf{0 . 4 5 5}(\mathbf{0 . 2 2 3})^{* *}$ & $0.119(0.316)$ & $0.889(0.550)$ \\
\hline Y06 & $\mathbf{- 0 . 4 2 8}(\mathbf{0 . 1 6 9}) * *$ & $0.275(0.281)$ & $-0.022(0.309)$ & $0.889(0.527)$ \\
\hline LAMBDA & & $-0.106(1.229)$ & & $-1.555(1.199)$ \\
\hline Correct \% & & Adj R $2: 0.320$ & $83.6 \%(74 \%)$ & Adj R : 0.361 \\
\hline Benchmark) & $69.37 \%(88 \%)$ & & $84.2 \%$ & \\
\hline Correct 1\% & $69.13 \%$ & & $78.3 \%$ & \\
\hline Correct 0\% & $71.09 \%$ & & & \\
\hline
\end{tabular}

Two-step regression model for administrative cases, using Heckman's correction for sample selection (** indicates statistical significance at $1 \%$ level, * at 5\% level):

\begin{tabular}{|c|c|c|c|c|}
\hline \multirow{5}{*}{ Variables } & \multicolumn{2}{|l|}{ HARM CASES } & \multicolumn{2}{|c|}{ NO HARM CASES } \\
\hline & PROBIT & SELECTION & PROBIT & SELECTION \\
\hline & $\begin{array}{l}\text { Dep Var } \\
\text { PROBADM }\end{array}$ & $\begin{array}{l}\text { Dep var } \\
\text { LNADMSANC }\end{array}$ & $\begin{array}{l}\text { Dep Var } \\
\text { PROBADM } \\
\end{array}$ & $\begin{array}{l}\text { Dep Var } \\
\text { LNADMSANC }\end{array}$ \\
\hline & \#obs: 276 & \#obs: 216 & \#Obs: 334 & \#Obs: 183 \\
\hline & Coeff. (Std.Err.) & $\begin{array}{l}\text { Coeff. in selection } \\
\text { group (Std.Err.) }\end{array}$ & Coeff. (Std.Err.) & $\begin{array}{r}\text { Coeff. in } \\
\text { selection group } \\
\text { (Std.Err.) }\end{array}$ \\
\hline ONE & $-0.554(0.501)$ & $2.905(0.599)^{* *}$ & $-0.004(0.415)$ & $5.926(0.351)^{*}$ \\
\hline INTENT & $-0.853(0.435)$ & $-0.313(0.477)$ & $-0.519(0.263)^{* *}$ & $0.111(0.188)$ \\
\hline REPEAT & $0.921(0.412)^{*}$ & $1.136(0.255)^{* *}$ & $0.095(0.269)$ & $0.531(0.112)^{*}$ \\
\hline PREWARN & $-0.152(0.292)$ & $0.747(0.267)^{* *}$ & $0.342(0.177)$ & $0.156(0.126)$ \\
\hline TECHNICAL & $-0.657(0.327)^{*}$ & $-0.006(0.315)$ & & \\
\hline HEALTH & $1.407(0.301)^{* * *}$ & $0.076(0.353)$ & & \\
\hline OFFENSES & $0.037(0.024)$ & $0.101(0.064)$ & $0.015(0.023)$ & $0.052(0.015)^{*}$ \\
\hline POSITIVE & $-1.387(0.272)^{* * *}$ & $-0.303(0.302)$ & $-1.505(0.166) *$ & $-0.060(0.479)$ \\
\hline ASBESTOS & & & $0.702(0.281)^{* * *}$ & $-0.098(0.222)$ \\
\hline WASTE & & & $0.421(0.194)^{* * *}$ & $0.106(0.155)$ \\
\hline SOILWATER & $-0.109(0.326)$ & $0.307(0.306)$ & & \\
\hline
\end{tabular}




\begin{tabular}{|c|c|c|c|c|}
\hline ODORAIR & $0.303(0.374)$ & $-0.746(0.338) *$ & $-0.088(0.352)$ & $-0.111(0.139)$ \\
\hline PROFESSIONAL & $1.194(0.471)^{*}$ & $1.276(0.480)^{* *}$ & $-0.017(0.406)$ & $0.207(0.189)$ \\
\hline FACILITY & $1.088(0.452)^{*}$ & $1.714(0.479)^{* *}$ & $0.310(0.393)$ & $0.243(0.204)$ \\
\hline AIRPLANE & $0.590(0.462)$ & $1.588(0.292)^{* *}$ & & \\
\hline Y05 & $0.154(0.305)$ & $0.286(0.263)$ & $0.437(0.191)^{* *}$ & $-0.003(0.156)$ \\
\hline Y06 & $0.208(0.320)$ & $0.147(0.267)$ & $0.481(0.209)^{* *}$ & $0.043(0.168)$ \\
\hline LAMBDA & & $1.217(0.466)^{* *}$ & & $0.221(0.386)$ \\
\hline $\begin{array}{l}\text { Correct \% } \\
\text { (Benchmark) }\end{array}$ & $\begin{array}{l}85.5 \% \\
(78 \%)\end{array}$ & Adj R²: 0.686 & $\begin{array}{l}78.1 \% \\
(55 \%)\end{array}$ & Adj R²: 0.263 \\
\hline Correct $1 \%$ & $86.6 \%$ & & $79.8 \%$ & \\
\hline Correct $0 \%$ & $81.7 \%$ & & $76.2 \%$ & \\
\hline
\end{tabular}

